\title{
Partial deficiency of HIF-1a stimulates pathological cardiac changes in streptozotocin-induced diabetic mice
}

\author{
Romana Bohuslavova ${ }^{1}$, Frantisek Kolar ${ }^{2}$, David Sedmera ${ }^{2,3}$, Lada Skvorova ${ }^{1}$, Frantisek Papousek ${ }^{2}$, Jan Neckar ${ }^{2}$
} and Gabriela Pavlinkova ${ }^{1,4^{*}}$

\begin{abstract}
Background: Diabetic cardiomyopathy is associated with a number of functional and structural pathological changes such as left ventricular dysfunction, cardiac remodeling, and apoptosis. The primary cause of diabetic cardiomyopathy is hyperglycemia, the metabolic hallmark of diabetes. Recent studies have shown that a diabetic environment suppresses hypoxia-inducible factor (HIF)-1a protein stability and function. The aim of this study was to analyze the functional role of HIF-1a in the development of diabetic cardiomyopathy. We have hypothesized that the partial deficiency of HIF-1 a may compromise cardiac responses under diabetic conditions and increase susceptibility to diabetic cardiomyopathy.

Methods: Diabetes was induced by streptozotocin in wild type $(\mathrm{Wt})$ and heterozygous Hifla knock-out (Hifla ${ }^{+/}$) mice. Echocardiographic evaluations of left ventricular functional parameters, expression analyses by qPCR and Western blot, and cardiac histopathology assessments were performed in age-matched groups, diabetic, and non-diabetic Wt and Hifla ${ }^{+/}$mice.
\end{abstract}

Results: Five weeks after diabetes was established, a significant decrease in left ventricle fractional shortening was detected in diabetic Hifla $a^{+-}$but not in diabetic Wt mice. The combination effects of the partial deficiency of Hifla and diabetes affected the gene expression profile of the heart, including reduced vascular endothelial growth factor A (Vegfa) expression. Adverse cardiac remodeling in the diabetic Hifla ${ }^{+/}$heart was shown by molecular changes in the expression of structural molecules and components of the extracellular matrix.

Conclusions: We have shown a correlation between heterozygosity for Hifla and adverse functional, molecular, and cellular changes associated with diabetic cardiomyopathy. Our results provide evidence that HIF-1a regulates early cardiac responses to diabetes, and that HIF-1a deregulation may influence the increased risk for diabetic cardiomyopathy.

Keywords: Echocardiographic parameters, Hypoxia inducible factor 1a, Diabetic cardiomyopathy, Vascular endothelial growth factor A, Heterozygous Hifla knock-out

\footnotetext{
* Correspondence: gpavlinkova@img.cas.cz

${ }^{1}$ Institute of Biotechnology AS CR, Prague, Czechia

${ }^{4}$ Laboratory of Molecular Pathogenetics, Institute of Biotechnology AS CR,

v.v.i., Videnska 1083, Prague 4, CZ-142 20, Czechia

Full list of author information is available at the end of the article
} 


\section{Background}

Both type 1 and type 2 diabetes are characterized by an increased risk of cardiomyopathy and myocardial infarction. Diabetic cardiomyopathy is associated with a number of functional and structural pathological changes, including decreased diastolic compliance, systolic dysfunction, apoptosis, and cardiac remodeling [1]. Diabetes is also associated with the majority of risk factors for cardiac failure, such as hypertension, hyperlipidemia, obesity, thrombosis, autonomic neuropathy, endothelial dysfunction, and microvascular pathology [2-4]. Hyperglycemia triggers diabetic tissue damage, including cardiovascular and microvascular complications. Existing evidence suggests that hyperglycemia induces an altered metabolism, abnormal expression of genes, the overproduction of reactive oxygen species (ROS), and mitochondrial dysfunction, which are underlying mechanisms behind pathological changes in diabetes [3]. Hypoxia is one of the most important pathophysiological factors associated with diabetic complications.

Transcriptional responses to hypoxia are mediated by hypoxia inducible factor 1 (HIF-1). HIF-1 activates over 800 target genes that are involved in cell proliferation, angiogenesis, glycolytic energy metabolism, and apoptosis [5]. HIF-1 consists of two subunits, HIF-1 $\alpha$, the regulatory subunit, and constitutively expressed HIF-1 $\beta$. Oxygen tension plays a key role in the regulation of HIF- $1 \alpha$ expression, stabilization, and activation [5]. The bulk of this response can be further modulated by growth factor and cytokine dependent signaling pathways [6,7]. Furthermore, existing evidence indicates that mitochondrial ROS are sufficient enough to initiate the stabilization and activation of HIF- $1 \alpha$, and that treatment with antioxidants prevents HIF- $1 \alpha$ protein stabilization [8,9]. Embryonic lethality due to cardiovascular defects resulting from the global deletion of HIF-1 $\alpha$ illustrates the critical role of Hifla in embryonic development [10]. Hifla ${ }^{+/}$mutants normally survive past embryonic development; however, Hifla heterozygotes demonstrate impaired responses when challenged with hypoxia after birth $[11,12]$. A partial deficiency of HIF- $1 \alpha$ has been associated with a complete loss of cardioprotection against ischemia-reperfusion injury, including the impairment of functional recovery parameters, a lack of ROS generation, and increased apoptosis [13]. Cardiac myocyte-specific HIF- $1 \alpha$ gene deletion causes reductions in contractility, vascularization, and alters the expression of multiple genes in the heart during normoxia [14]. These findings point toward the central role of HIF$1 \alpha$ in coordinating molecular, cellular, and functional responses in the heart and, also, toward the central role of HIF- $1 \alpha$ in diseases with impaired oxygen delivery, such as diabetes.

The diabetic environment reduces HIF-1 $\alpha$ expression and function [15-18]. Consistent with a negative effect of diabetes on HIF- $1 \alpha$ function, decreased levels of one of the best-known HIF-1 targets, VEGF-A, have been detected in diabetic hearts and other tissues [19]. In fact, the down-regulation of VEGF-A in diabetic hearts is the earliest event detected during diabetic cardiomyopathy and it is associated with the initiation of all the other features of diabetic cardiomyopathy, such as apoptosis, fibrosis, and progressive diastolic and systolic dysfunction [20]. Dysfunction of the left ventricle (LV) in diabetic cardiomyopathy has been correlated with cardiac remodeling, which leads to myocardial collagen deposition and cardiac fibrosis [21]. The causal relationship between decreased VEGFA expression, HIF- $1 \alpha$ functional activity, and high glucose-induced microvascular pathology has been revealed in experiments with a wound healing mouse model [18]. Interestingly, an impaired ability to increase hypoxia-stimulated VEGF-A expression in diabetic tissues resulted from a primary defect in HIF-1 transactivation but not HIF-1 stabilization. HIF1 activity increased by a local adenovirus-mediated transfer of stable HIF- $1 \alpha$ constructs normalizes VEGF-A expression and prevents diabetic complications $[15,16]$. Cardiac-specific HIF-1 $\alpha$-overexpressing transgenic mice show cardiac protection from diabetes-induced defects in glucose metabolism and angiogenesis [22]. HIF- $1 \alpha$ overexpression has restored VEGF-A levels and blocked cardiac fibrosis in the diabetic heart. However, the functional parameters of the LV have not been evaluated, which would be necessary for a more complex analysis.

Our study examines the relationship between the development of diabetic cardiomyopathy and the partial deficiency of HIF1- $\alpha$ caused by the global deletion of Hifla functional allele. We have hypothesized that the partial deficiency of Hifla may compromise cardiac responses under diabetic conditions and increase susceptibility to diabetic cardiomyopathy. Our research provides a new insight into the potential role of HIF- $1 \alpha$ and Hifla genetic variations in multiple pathways in diabetic cardiomyopathy. We analyzed echocardiographic parameters and molecular changes in the early phase of diabetic cardiomyopathy. We evaluated the expression of six HIF-1 transcriptional targets in order to identify signaling pathways and genes that may contribute to cardiac changes accompanying diabetes-induced cardiomyopathy and to directly evaluate HIF1-pathway responses. These genes encode molecules involved in vasculogenesis, glucose metabolism, insulin signaling, and autophagy (Vegfa, Flt1, Slc2a1, Ldha, Igf2, and Bnip3l). Additionally, we evaluated the expression of structural molecules (Cxadr, Cx43) and molecules associated with cardiac remodeling (Col1, Pdgfra, Ctss, Tgfbrl, Itgav, and Il6st). Our data showed that the partial deficiency of the Hifla gene accelerated the progression of pathological changes induced 
by the diabetic environment in the heart, including significant changes in cardiac mechanical function and in cardiac gene expression.

\section{Methods}

\section{Experimental animals}

This study was conducted in accordance with the Guide for the Care and Use of Laboratory Animals (NIH Publication No. 85-23, revised 1996). The experimental protocol was approved by the Animal Care and Use Committee of the Institute of Molecular Genetics, the Czech Academy of Sciences. The experimental mice were housed in a controlled environment $\left(23^{\circ} \mathrm{C} ; 12\right.$-h light/dark cycle) with free access to water and a standard chow diet. All experiments were performed with male and female littermate mice that were either wild-type, $\mathrm{Hifla}^{+/+}(\mathrm{Wt})$ or heterozygous Hifla knock-out $\left(\mathrm{Hifla}^{+/}\right)$on a FVB background (strain code 207, Charles River). The heterozygous Hifla mutants have the Hifla $a^{\text {tmlihu }}$ mutant allele in which exon 2, encoding the bHLH domain of the Hifla gene, has been replaced by an intragenic deletion with a neomycin resistance $\left(n e o^{R}\right)$ gene [10]. The heterozygous Hifla deficient mice showed a partial loss of HIF- $1 \alpha$ protein expression levels [23,24]. Offspring of Wt $x \mathrm{Hifla}^{+/-}$matings were genotyped by PCR, using genomic DNA isolated from tails and amplifying neomycin (Neo) and Hifla exon 2 sequences $[10,25]$. Both Neo (463-bp) and Hifla (317-bp) sequences were amplified from the DNA of $\mathrm{Hifla}^{+/}$mice, whereas only Hifla sequences were amplified from the DNA of Wt mice $\left(\mathrm{Hifla}^{+/+}\right)$, respectively. The sequences of the Neo primers were $5^{\prime}$-ACTGGCTGCTATTGGGCGAAGTG-3' and 5' GTAAAGCACGAGGAAGCGGTCAG-3'. The conditions for PCR were $94^{\circ} \mathrm{C}$ for $30 \mathrm{~s}, 48^{\circ} \mathrm{C}$ for $30 \mathrm{~s}$, and $72^{\circ} \mathrm{C}$ for $30 \mathrm{~s}$, for 40 cycles. The sequences of Hifla exon 2 primers were $5^{\prime}$-TGTAGTCTCCTGCTAAAAG-3' and 5 '-TTATTCGAGTTAAGACAAAC-3'. The conditions for PCR were $94^{\circ} \mathrm{C}$ for $30 \mathrm{~s}, 63^{\circ} \mathrm{C}$ for $30 \mathrm{~s}$, and $72^{\circ} \mathrm{C}$ for $30 \mathrm{~s}$, for 40 cycles.

Diabetes was induced in mice 8-10 weeks of age by 2 intraperitoneal injections of $100 \mathrm{mg} / \mathrm{kg}$ body weight of streptozotocin (STZ; Sigma, St. Louis, MO), as described in [26]. The fasting blood glucose levels were measured by glucometer (COUNTOUR TS, Bayer, Switzerland) one week after the last STZ injection. Mice whose blood glucose levels exceeded $13.9 \mathrm{mmol} / \mathrm{L}$ were considered diabetic. The mice were analyzed after being diabetic for 5 weeks. The fasting blood glucose levels (mean $\pm \mathrm{SD}$ ) of $\mathrm{Wt}$ and $\mathrm{Hifla}^{+-}$mice were $9.9 \pm 0.3$ and $10.0 \pm 0.3 \mathrm{mmol} / \mathrm{L}$ before STZ treatment, and $32.5 \pm 1.8$ and $30.3 \pm 2.0 \mathrm{mmol} / \mathrm{L}$ after 5 weeks of diabetes, respectively.

\section{Echocardiography}

The echocardiographic evaluation of the geometrical and functional parameters of the LV was performed using the
GE Vivid 7 Dimension (GE Vingmed Ultrasound, Horten, Norway) with a $12 \mathrm{MHz}$ linear matrix probe M12L. The animals were anesthetized by the inhalation of $2 \%$ isoflurane (Aerrane, Baxter SA) and their rectal temperature was maintained within 36.5 and $37.5^{\circ} \mathrm{C}$ by a heated table throughout the measurements. For the baseline evaluation, the following diastolic and systolic dimensions of the LV were measured: the posterior wall thickness $\left(\mathrm{PWT}_{\mathrm{D}}\right.$ and $\left.\mathrm{PWT}_{\mathrm{S}}\right)$, anterior wall thickness $\left(\mathrm{AWT}_{\mathrm{D}}\right.$ and $\left.A W T_{S}\right)$, and the cavity diameter $\left(\mathrm{LVD}_{\mathrm{D}}\right.$ and $\left.\mathrm{LVD}_{\mathrm{S}}\right)$. From these dimensions, the main functional parameter, fractional shortening (FS) was derived by the following formula: FS [\%] $=100 \times\left(\mathrm{LVD}_{\mathrm{D}}-\mathrm{LVD}_{\mathrm{S}}\right) / \mathrm{LVD}_{\mathrm{D}}$.

After the echocardiographic examination, a fluid filled catheter connected to an external transducer (Bpr-02, Experimetria) was introduced into the left carotid artery to measure the blood pressure. The mean blood pressure was averaged from five measurements within a 10-min interval. The hearts were then rapidly excised and dissected into the right ventricle (RV), the LV and the interventricular septum. All ventricular parts were weighed and processed for subsequent analyses.

\section{Quantitative real-time PCR}

RNA was isolated from the LV of individual diabetic and non-diabetic adult males (8 individual samples/each group) by Trizol ${ }^{\circledR}$ (Invitrogen). The concentration of extracted RNA was quantified using NanoDrop. Quantitative Real-Time PCR (RT-qPCR) was performed using the LightCycler $^{\circledR} 480$ Real-Time PCR system (Roche, Roche Applied Science, Mannheim, Germany) on cDNA samples. The collected RNA samples $(1 \mu \mathrm{g})$ were subjected to reverse transcription using Superscript II (Fermentas, Lithuania). cDNA was diluted $20 \times$ and $4 \mu \mathrm{l}$ were added to $6 \mu$ l of Syber ${ }^{\circledR}$ Green JumpStart ${ }^{\text {tix }}$ Tag ReadyMix ${ }^{\text {mi }}$ (Sigma) with primers $(0.25 \mu \mathrm{mol})$. Following the reverse transcription (RT), quantitative real-time PCR (qPCR) was performed with the initial AmpliTaq activation at $95^{\circ} \mathrm{C}$ for $10 \mathrm{~min}$, followed by 40 cycles at $95^{\circ} \mathrm{C}$ for $15 \mathrm{~s}$ and $60^{\circ} \mathrm{C}$ for $60 \mathrm{~s}$, as described in [25]. The Hprt1 gene was selected as the best reference gene for our analyses from a panel of 12 control genes (TATAA Biocenter AB, Sweden). The expression of this reference gene was unchanged in response to the experimental conditions being investigated. The relative expression of the target gene was calculated using the $\Delta \Delta \mathrm{Cp}$ method, based on qPCR efficiencies $(\mathrm{E})$ and the crossing point $(\mathrm{Cp})$ difference $(\Delta)$ of an experimental sample (diabetic $W t$, non-diabetic and diabetic $\mathrm{Hifla}^{+-}$) versus control-non-diabetic Wt (ratio =

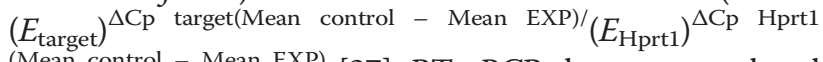
(Mean control - Mean EXP) [27]. RT-qPCR data were analyzed using the GenEX5 program (www.multid.se/genex). The differences in normalized $\mathrm{Cp}$ values were tested for statistical significance. The primers were designed using the 
Primer 3 software (http://bioinfo.ut.ee/primer3/). Primer sequences are listed in Additional file 1: Table S1.

\section{Morphological analysis}

The adult hearts of diabetic and non-diabetic $W t$ and $\mathrm{Hifla}^{+/-}$males were arrested in diastole by coronary perfusion with saline containing $5 \mathrm{mM}$ cadmium chloride and $20 \mathrm{mM}$ potassium chloride. After fixation with $4 \%$ paraformaldehyde overnight, the hearts were processed for paraffin histology. Adjacent sections $(7 \mu \mathrm{m})$ were stained with Alcian Blue/Hematoxylin-Eosin (general histological staining), Picrosirius Red (PSR, collagen), TUNEL (apoptosis; \#1684795, Roche), anti-collagen 1 (anti-Col1; \#203002, MD Biosciences), anti-smooth muscle actin (\#A 2574, Sigma), anti-CD34 (blood vessels; \#ab8158, Abcam), antiVEGF-A (\#sc-7269, Santa Cruz Biotechnology), and anticonnexin43/wheat germ agglutinin (anti-Cx43/WGA; gap junctions and cell membranes; \#C6219, Sigma/\#W7024, Invitrogen). The nuclei were counterstained with Hoechst 33342 in fluorescence techniques or hematoxylin in diaminobenzidine (DAB; \#D3939, Sigma) visualization protocol. Myocyte size (minimum transverse diameter) was measured on sections stained with anti-CD34 visualized by DAB. The cardiomyocytes can be best approximated as rodshape with an oval cross section. Any errors due to a variation of the section plane are avoided by choosing the minor axis only in cells where a nucleus is present. Each analysis was repeated a minimum of 2 times on 2-3 individual samples per genotype and included appropriate controls. The sections were analyzed under a Nikon Eclipse E400 fluorescent microscope or Leica SPE confocal microscope with a $40 \times$ magnification oil immersion objective, with NIS-elements or LCS program. VEGF-A ${ }^{+}$ areas were quantified using Image $J$ software. The evaluator of the VEGF-A expression was blinded to the experimental conditions and genotype.

\section{Western blot}

Dissected LVs from the diabetic and non-diabetic hearts were lysed with protease and phosphatase inhibitors to prevent protein degradation and stored at $-80^{\circ} \mathrm{C}$ until analysis. For HIF1- $\alpha$ immunoblot assays, nuclear extracts from dissected LVs were prepared using a Nuclear extract kit (\#40010; Active Motif, Belgium). The protein levels were quantified using the BCA assay. $20 \mu \mathrm{g}$ of total protein lysates or $30 \mu \mathrm{g}$ of nuclear extracts per lane were denatured, resolved using 10\% SDS-PAGE, and transferred to a nitrocellulose membrane $[10,28]$. The membrane was blocked with 5\% dry milk and incubated overnight with rabbit anti-Col1 at 1: 1000 dilution (\#203002; MD bioproducts, Switzerland), anti-Cx43 at 1:6000 (\#C6219, Sigma), anti-HIF-1 $\alpha$ at 1:750 dilution (\#NB100-105; Novus 224 Biologicals, UK), or anti-phospho-Cx43 at 1:1000 (\#3511; Cell Signaling, MA, USA). After incubation with a horseradish peroxidase-conjugated secondary IgG (Amersham, IL, USA), the blots were developed using the SuperSignal* West Dura Chemiluminescent Substrate (\#PIA34075; Thermo Scientific, MI, USA). Chemiluminescent signals were captured using an ImageQuant LAS 4000 Imager (GE Healthcare Bio-Sciences AB, Sweden) and analyzed by ImageJ software (http://rsbweb.nih.gov/ij/). Protein levels were quantified on duplicate blots and were normalized to the loading control mitochondrial membrane marker (ATP5a) or glyceraldehyde 3-phosphate dehydrogenase (GAPDH; Membrane Fraction WB Cocktail, \#ab140365; Abcam, Cambridge, USA).

\section{Statistical analysis}

All values are expressed as mean \pm SEM. Group data were analyzed using 2-way ANOVA (with genotype and experimental condition as categories) and Tukey's posthoc multiple-comparisons test for between-group differences (significance assigned at the $P<0.05$ level; Graph Pad, 2005; Graph Pad, San Diego, CA). Sample sizes and individual statistical results for all analyses are provided in the figures and tables.

\section{Results}

\section{Echocardiographic evaluation of the LV function}

Five weeks after diabetes was induced by repeated intraperitoneal STZ injections, the body mass and LV mass gains of diabetic $\mathrm{Hifla}^{+/-}$and $\mathrm{Wt}$ males were lower compared to non-diabetic groups (Table 1). Diabetic females were less affected in the body and LV mass gains than diabetic males. Neither heart rate nor blood pressure differed among the groups, although blood pressure tended to increase in both $\mathrm{Wt}$ and $\mathrm{Hifla}^{+/-}$diabetic mice compared to the corresponding controls (males: $P=0.053$ and 0.066 , respectively, Table 2). LV echocardiography did not reveal any difference between non-diabetic $W t$ and $\mathrm{Hifla}^{+/-}$mice. However, diabetes significantly influenced the LV echocardiographic parameters of $\mathrm{Hifla}^{+/-}$ mice. The general trends of functional changes induced by diabetes were similar in males and females (Figure 1 and Table 2). LV FS was unaffected by genotype in nondiabetic Wt (males: $38.3 \pm 0.6$, females: $33.8 \pm 1.3$ ) and non-diabetic $\mathrm{Hifla}^{+/-}$mice (males: $38.0 \pm 0.9$, females: $33.6 \pm 0.6$, Figure 1A). A significant decrease in LV FS was detected in diabetic $\mathrm{Hifla}^{+/-}$mice (males: $33.8 \pm 1.2$, females: $29.8 \pm 1.0$ ) but not in diabetic $W t$ animals (males: $36.9 \pm 0.8$, females: $32.8 \pm 0.9$, Figure $1 \mathrm{~A})$. The differences in LV FS between non-diabetic and diabetic $\mathrm{Hifla}^{+/-}$mice are also shown in representative M-mode echocardiographic recording (Figure $1 \mathrm{~B}$ and $\mathrm{C}$ ). Both diastolic and systolic AWT and PWT were significantly lower in diabetic $\mathrm{Hifla}^{+/-}$males than in non-diabetic Wt and $\mathrm{Hifla}^{+/-}$males. Although we observed similar tendencies in AWT and PWT parameters in diabetic Wt 
Table 1 Body and heart mass

\begin{tabular}{|c|c|c|c|c|}
\hline Genotype & $W t$ & Wt & Hifla $^{+/-}$ & Hif1 $^{+/-}$ \\
\hline Parameter & Non-diabetic & Diabetic & Non-diabetic & Diabetic \\
\hline Males (n) & 7 & 8 & 10 & 8 \\
\hline $\mathrm{BM}(\mathrm{g})$ & $28.0 \pm 0.4$ & $24.8 \pm 0.7^{*}$ & $28.4 \pm 0.6$ & $22.9 \pm 0.8^{*^{\dagger}}$ \\
\hline $\mathrm{HM}$ (mg) & $106 \pm 2$ & $88 \pm 3^{*}$ & $104 \pm 4$ & $86 \pm 3^{*^{\dagger}}$ \\
\hline $\mathrm{RV} / \mathrm{BM}$ & $0.77 \pm 0.03$ & $0.74 \pm 0.04$ & $0.76 \pm 0.04$ & $0.73 \pm 0.02$ \\
\hline LV/BM & $2.18 \pm 0.03$ & $1.98 \pm 0.06^{*}$ & $2.07 \pm 0.04$ & $1.96 \pm 0.03^{*}$ \\
\hline Females (n) & 7 & 12 & 10 & 8 \\
\hline $\mathrm{BM}(\mathrm{g})$ & $22.0 \pm 0.7$ & $22.1 \pm 0.6$ & $22.1 \pm 0.5$ & $20.5 \pm 0.4$ \\
\hline $\mathrm{HM}$ (mg) & $81 \pm 1$ & $80 \pm 1$ & $79 \pm 2$ & $77 \pm 1$ \\
\hline $\mathrm{RV} / \mathrm{BM}$ & $0.80 \pm 0.04$ & $0.80 \pm 0.02$ & $0.74 \pm 0.02$ & $0.73 \pm 0.03$ \\
\hline LV/BM & $2.34 \pm 0.07$ & $2.31 \pm 0.08$ & $2.26 \pm 0.05$ & $2.34 \pm 0.14$ \\
\hline
\end{tabular}

Values are means \pm SEM from indicated number of animals in each group. Abbreviations: BM, body mass; HM, heart mass; LV, left ventricular mass; RV right ventricular mass. Statistical significance was assessed by 2-way ANOVA with Tukey's multiple-comparison test, ${ }^{*} \mathrm{P}<0.05$ vs. non-diabetic $W t ;{ }^{\dagger} P<0.05$ vs. non-diabetic Hif1a ${ }^{+/}$.

Table 2 Mean systemic arterial blood pressure (MAP), heart rate (HR) and basal left ventricular echocardiographic parameters

\begin{tabular}{|c|c|c|c|c|}
\hline Genotype & $W t$ & $W t$ & Hif1 $^{+/-}$ & $\begin{array}{l}\mathrm{Hif1}^{+/-} \\
\text {Diabetic }\end{array}$ \\
\hline Parameter & Non-diabetic & Diabetic & & Diabetic \\
\hline 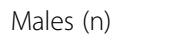 & 6 & 8 & 10 & 8 \\
\hline $\mathrm{AP}(\mathrm{mmHg})$ & $83.0 \pm$ & $8 / .5 \pm$ & 84.1 & $88.2 \pm 1.6$ \\
\hline R (beats/min) & $496 \pm 23$ & $471 \pm 13$ & $449 \pm 40$ & $440 \pm 36$ \\
\hline$/ D_{D}(m m)$ & $3.60 \pm$ & $3.59 \pm 0.04$ & $3.47 \pm$ & $3.65 \pm 0.06$ \\
\hline$V D_{S}(m m)$ & $2.22 \pm 0.07$ & $2.27 \pm 0.05$ & $2.16 \pm 0.08$ & $2.42 \pm 0.07$ \\
\hline $\mathrm{WT}_{\mathrm{D}}(\mathrm{mm})$ & $0.84 \pm 0.02$ & $0.76 \pm 0.01$ & $0.89 \pm 0.02$ & $0.74 \pm 0.03^{\dagger *}$ \\
\hline$N T_{D}(\mathrm{~mm})$ & $0.84 \pm 0.03$ & $0.76 \pm 0.01$ & $0.92 \pm 0.04$ & $0.69 \pm 0.03^{\dagger *}$ \\
\hline $\mathrm{WT}_{\mathrm{S}}(\mathrm{mm})$ & $1.30 \pm 0.03$ & $1.20 \pm 0.04$ & $1.27 \pm 0.03$ & $1.10 \pm 0.05^{* *}$ \\
\hline $\mathrm{WT}_{\mathrm{S}}(\mathrm{mm})$ & $1.21 \pm 0.03$ & $1.09 \pm 0.03$ & $1.20 \pm 0.04$ & $1.00 \pm 0.04^{\dagger *}$ \\
\hline emales (n) & 7 & 12 & 10 & 8 \\
\hline MAP $(\mathrm{mmHg})$ & $84.6 \pm 2.1$ & $88.5 \pm 2.2$ & $84.8 \pm 0.04$ & $88.1 \pm 1.3$ \\
\hline IR (beats/min) & $504 \pm 7$ & $478 \pm 15$ & $484 \pm 16$ & $449 \pm 17$ \\
\hline $\mathrm{LVD}_{\mathrm{D}}(\mathrm{mm})$ & $3.52 \pm 0.08$ & $3.52 \pm 0.06$ & $3.45 \pm 0.04$ & $3.46 \pm 0.04$ \\
\hline$-\mathrm{VD}_{\mathrm{S}}(\mathrm{mm})$ & $2.33 \pm 0.07$ & $2.37 \pm 0.06$ & $2.30 \pm 0.05$ & $2.43 \pm 0.06$ \\
\hline $\mathrm{AWT}_{\mathrm{D}}(\mathrm{mm})$ & 0.75 & 1 & 0.02 & $0.72 \pm 0.02$ \\
\hline $\mathrm{PWT}_{\mathrm{D}}(\mathrm{mm})$ & $0.79 \pm 0.02$ & $0.74 \pm 0.02$ & $0.78 \pm 0.03$ & $0.74 \pm 0.02$ \\
\hline $\mathrm{WT}_{\mathrm{S}}(\mathrm{mm})$ & $1.12 \pm 0.04$ & $5 \pm 0.02$ & $1.06 \pm 0.01$ & $0.98 \pm 0.02^{\dagger *}$ \\
\hline $\mathrm{PWT}_{\mathrm{S}}(\mathrm{mm})$ & $1.10 \pm 0.02$ & $1.05 \pm 0.02$ & $1.09 \pm 0.02$ & $0.99 \pm 0.02^{*}$ \\
\hline
\end{tabular}

Values are mean $\pm S E M$. $L_{V D}$ - diastolic cavity diameter, $\mathrm{LVD}_{\mathrm{S}}$ - systolic cavity diameter, $\mathrm{AWT}_{\mathrm{D}}$ - diastolic anterior wall thickness, $\mathrm{PWT}_{\mathrm{D}}$ - diastolic posterior wall thickness, $\mathrm{AWT}_{\mathrm{S}}$ - systolic anterior wall thickness, $\mathrm{PWT}_{\mathrm{S}}$ - systolic posterior wall thickness. Statistical significance was assessed by 2-way ANOVA with Tukey's multiple-comparison test, ${ }^{*} P<0.05$ vs. non-diabetic $W t^{\dagger} P<0.05$ vs. non-diabetic $\mathrm{Hifl}^{+/-}$.

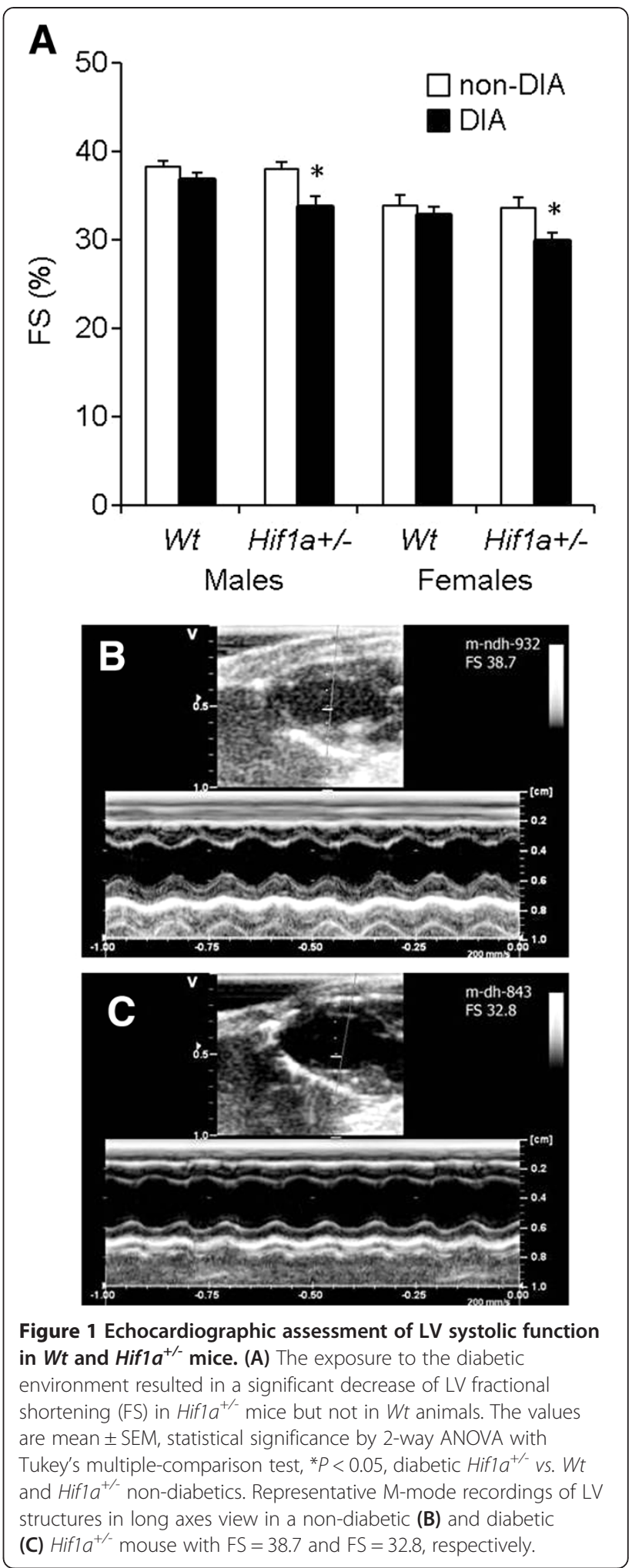

animals, these differences were not statistically significant. Thus, the partial deficiency of Hifla compromised the LV functional parameters under diabetic conditions. 
Since male groups were more affected in LV echocardiographic parameters by diabetes than female groups, we only used males for our subsequent analyses.

\section{Cardiac gene expression profiling}

To explore the tissue specific molecular changes induced by diabetes, we analyzed the expression of 13 selected genes in the LV myocardium (Figure 2). All tests showed a significant effect of diabetes. We analyzed the expression of six HIF-1 target genes involved in glucose metabolism (Ldha; Slc2a1), autophagy (Bnip3l), insulin signaling (Igf2) and vasculogenesis (Vegfa; Flt1; Figure 2A). Under normal conditions, the HIF-1 $\alpha$ heterozygous-null mutants showed a decreased cardiac transcription of three HIF-1 target genes, Vegfa, Igf2, and Ldha, reflecting Hif1a haploinsufficiency. The expression levels of mRNA of Vegfa were significantly affected by the combination of genotype and diabetes (2-way ANOVA interaction effect, $P<0.01$ ). The cardiac expression of Slc2a1, Flt1, and Bnip3l mRNA was significantly affected by diabetic conditions, but not by genotype. We also analyzed the expression of additional genes encoding molecules associated with cardiac remodeling (Figure 2B). The expression levels of Cxadr, Pdgfra, and Il6st were increased, whereas the expression of Itgav was decreased in both $\mathrm{Wt}$ and $\mathrm{Hifla}^{+/-}$diabetic hearts compared to the non-diabetics. Interestingly, Tgfbr1, Ctss, and transcription factor Gata2 levels were increased in the diabetic $\mathrm{Hifla}^{+/-}$, but not in the diabetic Wt hearts (a significant effect of genotype, $P<0.01$ ). Based on the gene expression analysis, we can conclude that the diabetic $\mathrm{Hifla}^{+/-}$hearts demonstrated molecular changes associated with transcriptional regulation and cardiac remodeling processes.

\section{Analysis of HIF-1a protein levels in the LV}

In the next step, HIF- $1 \alpha$ protein expression was analyzed in nuclear extracts from the LVs in order to understand the basis for the diabetes-induced changes in $\mathrm{Hifla}^{+/-}$ diabetic hearts. A representative example of the immunoblot assay and the mean data obtained from densitometric analysis are presented in Figure 3A. Protein analysis revealed that HIF1- $\alpha$ levels were decreased by $35 \%$ in the LV of $\mathrm{Hifla}^{+/-}$hearts compared to Wt. A significant condition-genotype interaction was identified $(P<0.003$, 2-way ANOVA). Unexpectedly, HIF-1 $\alpha$ levels were significantly increased in diabetes-exposed $\mathrm{Hifla}^{+/-}$ hearts compared to diabetes-exposed $\mathrm{Wt}$ and non-diabetic $\mathrm{Hifl}^{+/-}$mice by 2.6-fold and 2.1-fold, respectively. We detected a decreased HIF- $1 \alpha$ expression in the diabetic Wt heart, although the difference was not statistically significant compared to non-diabetic Wt $(P>0.05$, Figure 3B).

\section{Cellular and structural analysis}

We further investigated pathogenic molecular and cellular changes associated with diabetes-induced myocardial remodeling, characterized by structural modifications, increased extracellular matrix and fibrosis, increased cardiac hypertrophy, apoptosis, and microvascular changes. The expression and proportion of phosphorylated and dephosphorylated forms of structural gap-junctional protein Cx43 are altered in diabetic conditions [29]. In our study, the relative abundance of $\mathrm{Cx} 43$ was moderately decreased in the diabetic myocardium compared to nondiabetic groups (Figure 4A). The quantification of $\mathrm{Cx} 43$ protein levels by Western blot showed no significant differences between groups or genotypes (Figure $4 \mathrm{~B}$ and $\mathrm{C}$ ). However, the phosphorylated form of $\mathrm{Cx} 43$ at serine 368 ( $\mathrm{Ph}-\mathrm{Cx} 43)$ was significantly decreased in the diabetic $\mathrm{Hifla}^{+/-}$mutant LV (Figure 4D). Tissue sections from Wt and heterozygous $\mathrm{Hifla}^{+/}$hearts were subjected to histological analysis to evaluate perivascular fibrosis by collagen deposition (PSR and anti-Col1 staining, Figure 4A). Perivascular collagen deposition was not noticeably different in diabetics compared to non-diabetic groups (Figure 4A). However, Western blot analysis detected a significant increase in the protein levels of Col1 in the LV of diabetic $\mathrm{Hifla}^{+/-}$heart compared to other analyzed groups (Figure 4E). Quantitative measurements of myocyte width yielded identical values in all groups (data not shown), which confirmed the absence of hypertrophy at this stage.

Additionally, we analyzed levels of apoptosis using TUNEL staining. We counted apoptotic cells in the LV, RV, and septum. The number of apoptotic cells was moderately increased in the diabetic Wt but not in the diabetic $\mathrm{Hifla}^{+/-}$ hearts, which suggests that the $\mathrm{Hifla}^{+/-}$genotype affects the apoptotic process in diabetic hearts (Figure 5).

Since our RT-qPCR analysis demonstrated a significant combinatorial effect of genotype and diabetes on Vegfa mRNA expression, we analyzed the cardiac expression of VEGF-A, a key HIF-1 target gene product. VEGF-A is the essential modulator of neovascularization and diminished levels of VEGF-A have been associated with the impaired collateral vessel formation in the myocardial tissue of diabetic patients $[18,19]$. Using immunohistochemistry, we analyzed VEGF-A expression in histological sections of $\mathrm{Wt}$ and $\mathrm{Hifla}^{+/-}$hearts from diabetic and non-diabetic mice (Figure 6A). The anti-VEGF-A staining was found to be limited to the wall of coronary vessels in all groups. The relative quantification of VEGF-A expression in the wall of coronary vessels showed decreased protein levels by $50 \%$ in non-diabetic $\mathrm{Hifla}^{+/-}$compared to $\mathrm{Wt}$, corresponding to the haploinsufficiency of Hifla (Figure 6B). Furthermore, the VEGF-A protein levels were significantly reduced in the coronary vessels of diabetic $\mathrm{Hifla}^{+/-}$ and $W t$ compared to non-diabetic Wt, indicating microvascular changes in the diabetic heart. Overall, these data suggest that the partial deficiency of Hifla alters molecular and cellular adaptations of cardiac tissue to diabetic conditions. 

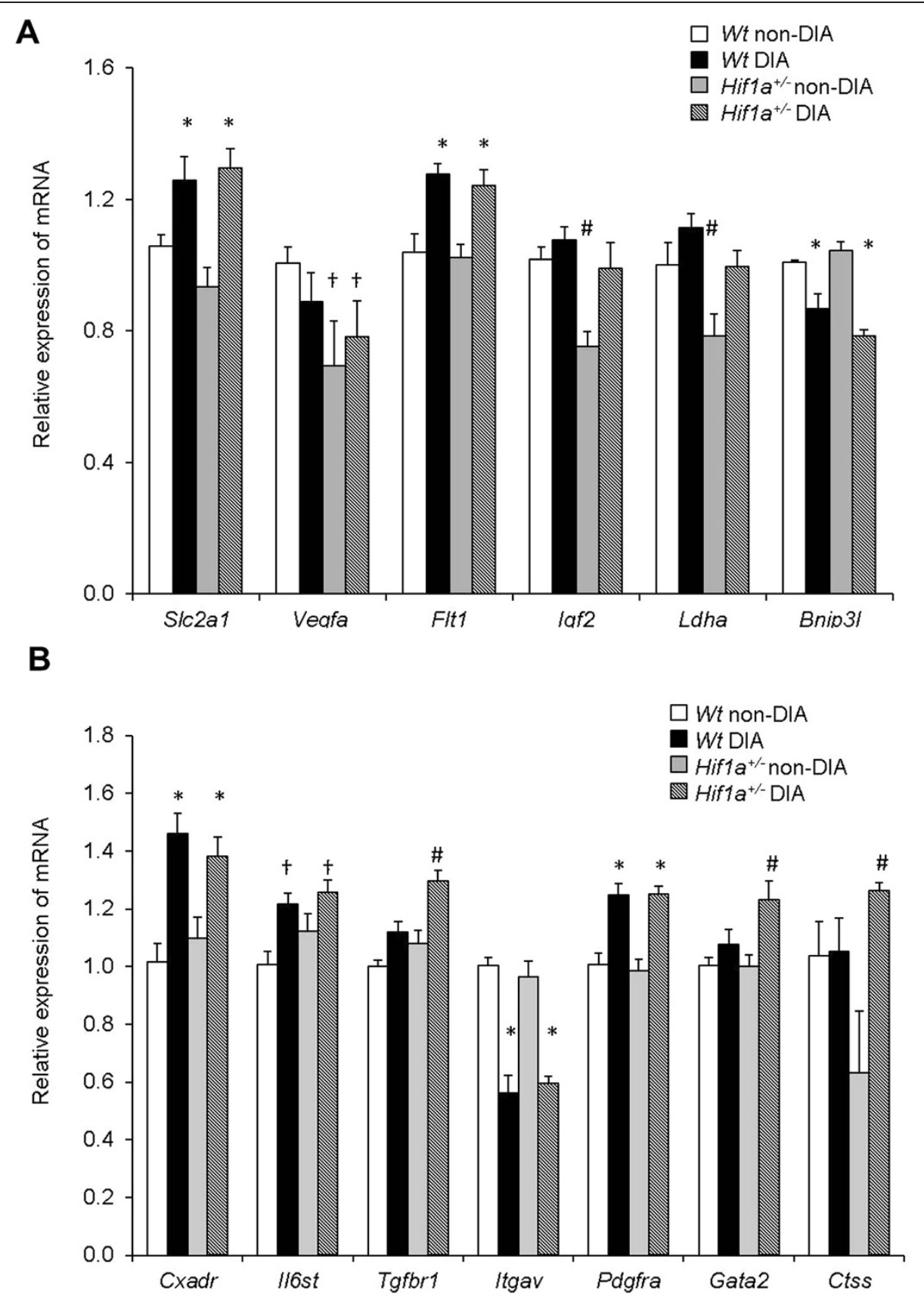

Figure 2 Gene expression changes in the LV of $\mathbf{W t}$ and Hif1 $a^{+-}$diabetic mice. The expression of genes was analyzed using RT-qPCR: (A) direct HIF-1a target genes and (B) genes encoding signaling molecules, growth factors, cytokines, and transcription factors. The relative expression levels were quantified using the $\Delta \Delta C T$ method. The data represent the expression of mRNA relative to the non-diabetic Wt expression of mRNA, normalized by the housekeeping mRNA of Hprt1. The values are mean \pm SEM (each experiment in duplicate; $n=8$ ). All tests showed a significant effect of diabetes in a 2-way ANOVA, $P<0.01$. The effect of genotype was significant in a 2-way ANOVA for lgf2 $(P<0.003), L d h a(P<0.0001)$, Tgfbr $(P<0.006)$, Gata2 $(P<0.01)$, Ctss $(P<0.05)$. We identified a condition-genotype interaction (2-way ANOVA interaction effect $P<0.01)$ for Vegfa. Tukey's post-hoc multiple-comparison test was used for between-group differences, ${ }^{*} P<0.05 \mathrm{vs}$. Wt and Hifl $a^{+-}$non-diabetics, ${ }^{\dagger} P<0.05 \mathrm{vs}$. non-diabetic Wt, ${ }^{\#} P<0.05 \mathrm{vs}$. all other groups. Abbreviations: glucose transporter 1 (S/c2a1), vascular endothelial growth factor A (Vegfa), Vegf receptor-1 (F/t 1), insulin-like growth factor 2 (Igf2), lactate dehydrogenase A (Ldha), BCL2/adenovirus E1B interacting protein 3-like (Bnip3), coxsackie virus and adenovirus receptor (Cxadr), interleukin 6 signal transducer (I/6st), transforming growth factor beta receptor I (Tgfor1), integrin alpha $\vee($ Itgav), platelet derived growth factor receptor alpha (Pdgfra), GATA binding protein 2 (Gata2), cathepsin S (Ctss). 


\section{Discussion}

This study investigated the functional role of HIF1pathways in cardiac responses to diabetic conditions, including changes in echocardiographic parameters, transcriptional profile modulations, and tissue remodeling. For the first time, we showed that the partial deficiency of Hifla accelerated the early-phase pathological effects of diabetes on the heart. The echocardiographic parameters of the LV were significantly affected in diabetic $\mathrm{Hifla}^{+/-}$ animals. Impaired LV function of diabetic $\mathrm{Hifla}^{+/}$mutants was accompanied by molecular changes associated with cardiac remodeling.

We used the STZ model which has been proved to produce diabetes in animal models without systemic toxicity and is characterized by hyperglycemia (blood glucose levels $>13.9$ ) and insulinopenia. Most studies using animal models with STZ-induced diabetes revealed a decreased myocardial contractility and increased stiffness, resulting in both systolic and diastolic dysfunction at later stages of the disease (reviewed in [30,31]). However, the onset of these changes, preceded by an altered gene expression, differs in individual studies and can be explained by differences in the severity of hyperglycemia, chronicity of diabetes, and experimental conditions. For example, both echocardiography and magnetic resonance imaging performed in the fourth week of diabetes in mice showed impaired indices of systolic and diastolic function [32]. Similarly, diabetic rats exhibited decreased maximal systolic elastance at this stage of diabetes, indicating impaired intrinsic myocardial contractility [33]. However, Hoit et al. [34] observed the first signs of contractile dysfunction in rats only 5 weeks after STZ injections and the overt systolic and diastolic dysfunction in 6 weeks. Consistent with this study, our experiments revealed only a minor decrease in relative LV wall thickness and unchanged fractional shortening in 5-week-diabetic Wt mice, indicating that heart function was still preserved at this stage. However, the harmful effects of diabetes were clearly more pronounced in $\mathrm{Hifla}^{+/-}$mice as illustrated by the significantly decreased FS. It suggests that $\mathrm{Hifla}^{+/-}$deficiency promotes the development of systolic dysfunction in the diabetes-exposed heart. The LV dysfunction in $\mathrm{Hifla}^{+/}$ mice was associated with expressional changes connected with cardiac remodeling. Our observations are in line with the increasing evidence that the HIF1-regulated pathways are compromised in the diabetic heart $[15,17,18]$.

Our molecular analysis showed increased levels of Cxadr, Il6st, Pdgfra, and Slc2a1 in the LV of both Wt and $\mathrm{Hifla}^{+/-}$diabetic hearts which corresponds to the onset of pathological processes associated with cardiac remodeling in diabetic cardiomyopathy. The overexpression of Cxadr, an adhesion molecule found at the intercalated disc and gap junctions of cardiomyocytes, produces cardiomyopathy in transgenic mice

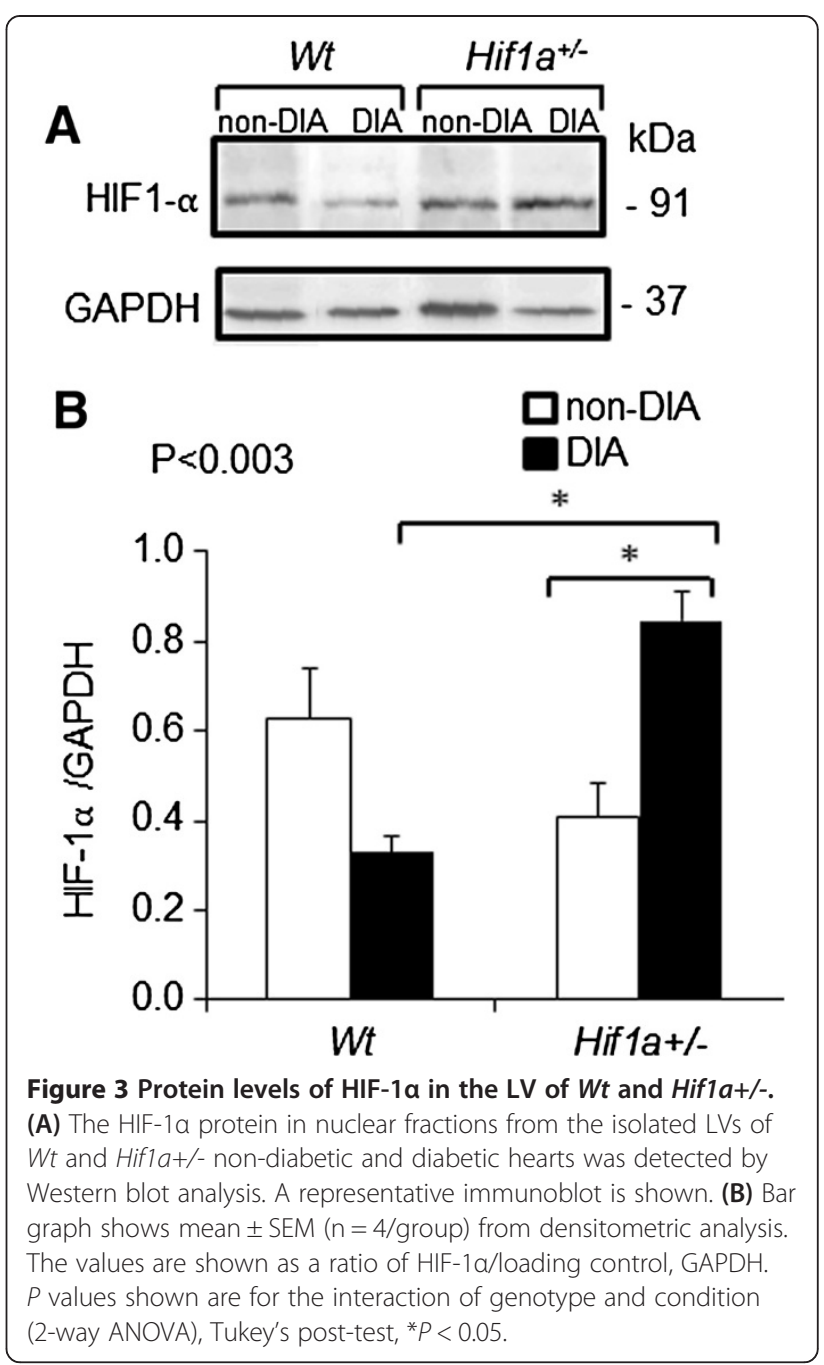

[35]. The transmembrane signal transduction protein gp130, encoded by Il6st, is a common receptor for the interleukin 6 family, which contributes to inflammatory processes, cardiac fibrosis, and possibly to the development of type 1 and type 2 diabetes [36]. The activation of PDGFR- $\alpha$ induces collagen deposition, fibrosis, and inflammatory responses in an infarcted myocardium [37]. Observed increased levels of Slc2a1, the insulinindependent glucose transporter, indicate an adaptation of the myocardium to the diabetic environment for better glucose uptake and utilization [38].

In our study, the combinatory effect of the $\mathrm{Hifla}^{+/}$genotype and diabetes was detected in the expression of Gata2, Ctss, and Tfgbr1. The transcriptional factor GATA2 cooperates with HIF1- $\alpha$ and complements HIF-1 transcriptional regulation of pro-inflammatory genes in endothelial cells $[39,40]$. Thus, the increase of Gata2 mRNA in the diabetic $\mathrm{Hifla}^{+/}$heart may indicate a compensation of HIF-1 $\alpha$ activity. Increased levels of Ctss positively correlate with extracellular matrix remodeling in the diabetic $\mathrm{Hifla}^{+/}$ 


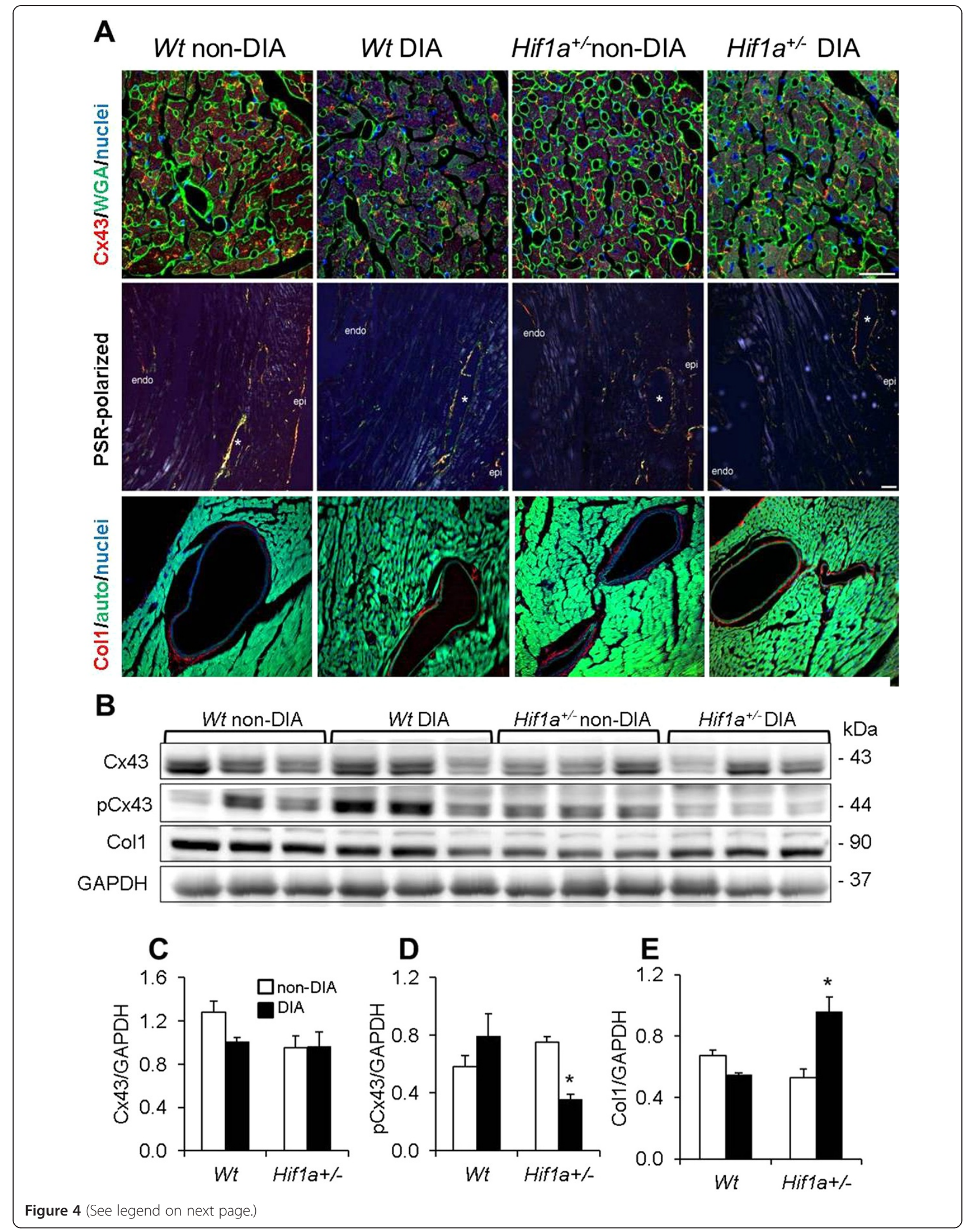


(See figure on previous page.)

Figure 4 Effects of diabetes on structural remodeling and protein levels in the Wt and Hif1 ${ }^{+/-}$LV. (A) Representative of immunofluorescence confocal and light microscopy images of the hearts stained with anti-connexin $43(\mathrm{C} \times 43$, red) together with fluorescein-labeled wheat germ agglutinin (WGA, green); with picrosirius red (PSR, polarizing microscopy); and with anti-collagen 1 (Col1, red), autofluorescence (auto) are shown. The nuclei were

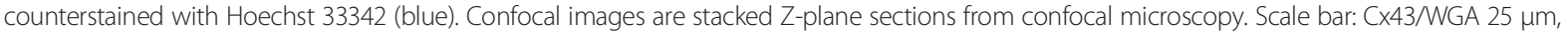
PSR $50 \mu \mathrm{m}$, Col1 $25 \mu \mathrm{m}$. (B) Representative Western blot analyses of protein lysates from the isolated LVs of Wt and Hif1 $a^{+/-}$non-diabetic and diabetic hearts are shown. (C-E) A relative quantification of protein levels of $\mathrm{C} \times 43$, phosphoC $\times 43$ ( $\mathrm{p} C \times 43)$, and Col1 ( $\mathrm{n}=3$ per group) was performed. The bar graphs show the mean values of relative protein levels normalized to the loading control (GAPDH) \pm SEM from densitometric analysis. ${ }^{*} P<0.05(2-$ way ANOVA with Tukey's post-test).

heart because CTSS protease is involved in matrix degradation and collagen deposition [41]. Although the important regulatory role of HIF- $1 \alpha$ in inflammation has been established [42], a cross-talk between CTSS and HIF-1 has not yet been observed. We showed an increased expression of Tgfbrl mRNA in the LV of the $\mathrm{Hifla}^{+/-}$diabetic hearts, suggesting the activation of TGF- $\beta$ signaling, which is associated with maladaptive changes in the composition of the extracellular matrix and fibrosis [43]. A cross-talk between TGF- $\beta$ and HIF-1 pathways has been shown in the transcriptional regulation of Vefga, and Col1 genes $[44,45]$.

In our study, the molecular changes associated with alterations of structural molecules and with the composition of the extracellular matrix were also shown in the protein levels. We detected a reduction in the gapjunctional phosphorylated form of Cx43 in the LV of the $\mathrm{Hifla}^{+/-}$diabetic heart, which has been associated with

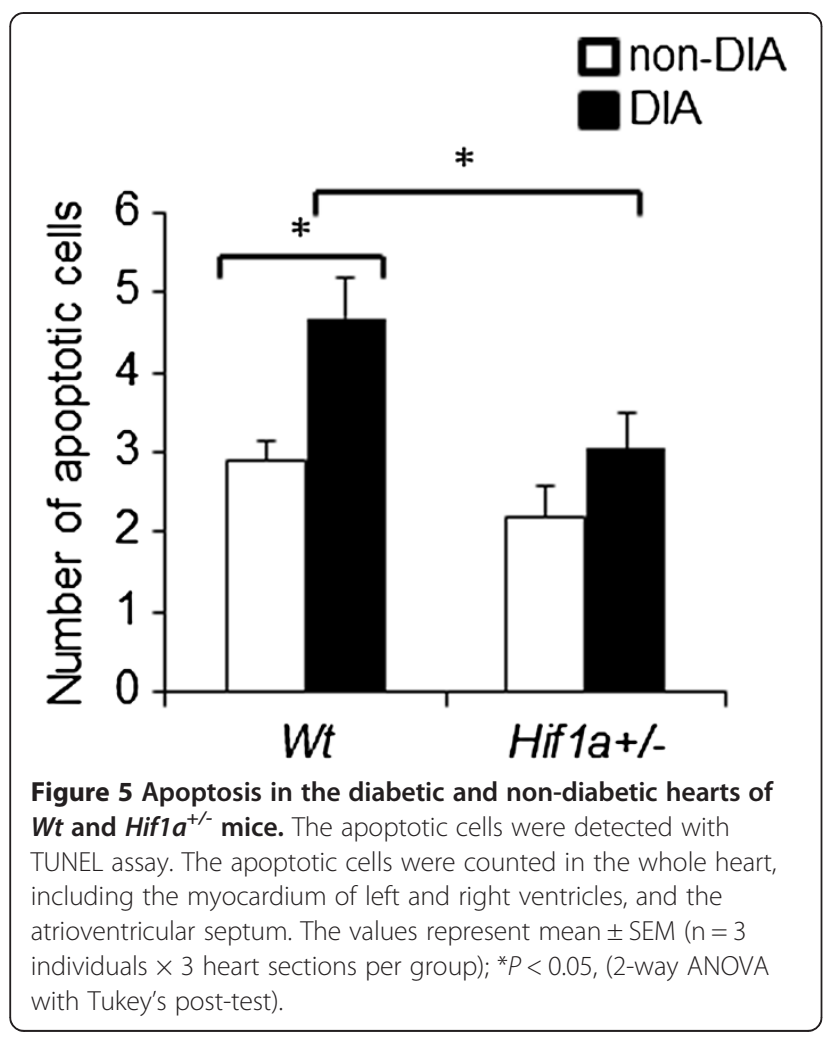

diabetes-induced structural remodeling and impaired ventricular contractions [29]. We also showed increased protein levels of Col1 in $\mathrm{Hifla}^{+/-}$diabetic hearts compared to other groups, indicating modifications of the extracellular matrix and the onset of fibrosis. However, our immunohistological analysis revealed that the substantial cellular effects of hyperglycemia, including myocyte hypertrophy or fibrosis, were absent at this stage of diabetic cardiomyopathy. This phenotype reconciles with STZ-induced diabetes models characterized by the impaired LV function in the absence of significant structural changes in the early phase of diabetic cardiomyopathy [31].

Under normal conditions, apoptosis is a protective mechanism which eliminates old, useless, and damaged cells. Under diabetic conditions, increased apoptosis is associated with diabetes-related tissue damage and cardiac remodeling in diabetic hearts [46]. Surprisingly, we observed an increased number of apoptotic cells in the diabetes-exposed Wt hearts but not in the $\mathrm{Hifla}^{+/-}$hearts. The decreased sensitivity of $\mathrm{Hifla}^{+/-}$cardiac tissue to apoptosis-induction signals may be a consequence of the HIF- $1 \alpha$ partial deficiency to induce apoptosis via p53, BNIP3, or/and caspase3 pathways. However, additional studies are required to determine which signaling pathways mediate these effects in the diabetic Hifla ${ }^{+/-}$heart.

Diabetic microvascular defects, associated with the increased incidence of chronic wounds and decreased postischemic vascularization, have been accompanied by a significant reduction of VEGF-A, a key HIF-1 target gene product $[18,19,47]$. Decreased levels of VEGF-A mRNA have been detected in the ventricles of diabetic patients when compared to controls [19]. The observed reduction of cardiac VEGF-A levels correlated with pathologically altered responses of diabetic patients to myocardial ischemia. In our study, we demonstrated the significantly decreased expression of Vegfa mRNA in diabetic $\mathrm{Hifla}^{+/-}$ compared to diabetic $W t$ mice. Both transcription and RNA stability can be enhanced by HIF-1 $\alpha$ in response to normal as well as pathological conditions [48]. We observed discrepancies in the amplitude of mRNA and protein levels in $\mathrm{Hifla}^{+/}$and $\mathrm{Wt}$ diabetic hearts. Although we are unable to explain these discrepancies, they are likely caused by the specific regulation of VEGF-A at 

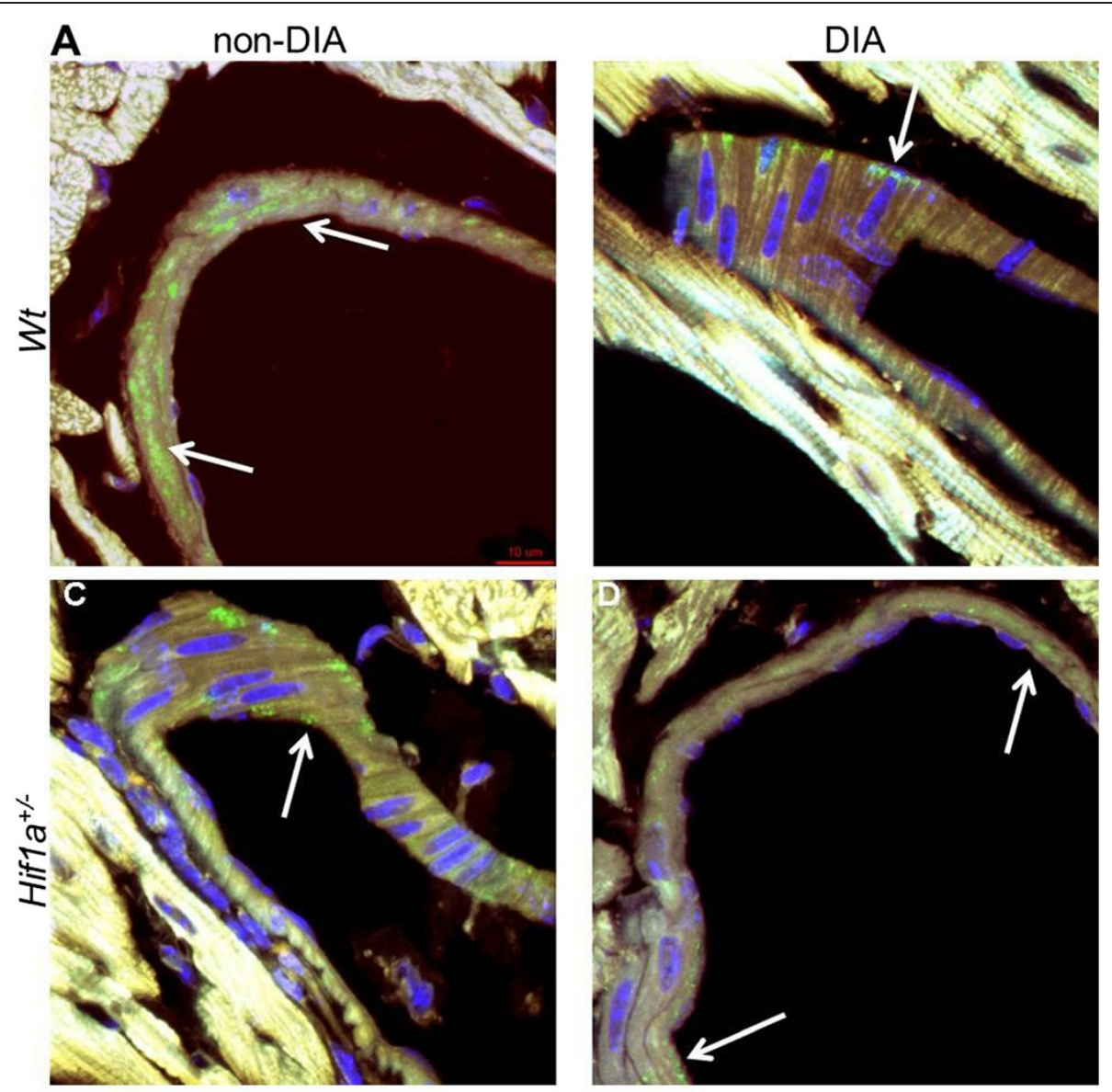

\section{B}

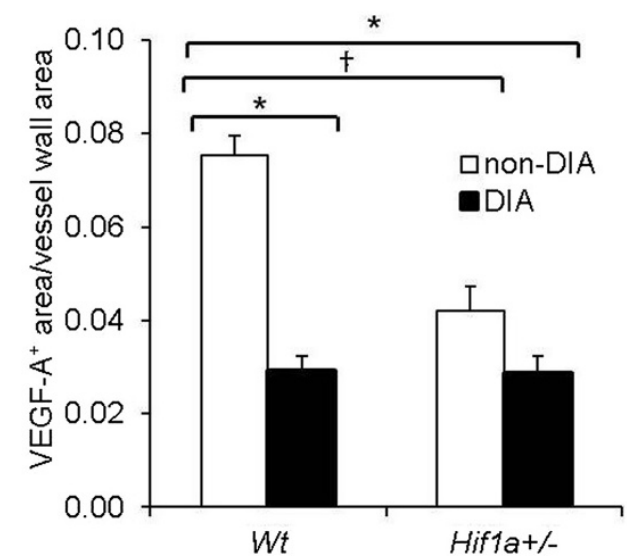

Figure 6 Diabetes-induced changes in cardiac VEGF-A expression. (A) Confocal imaging of transverse sections of Wt and Hifla ${ }^{+/}$hearts stained with anti-VEGF-A antibody (green) showed VEGF-A expression in coronary blood vessels (white arrow). Hoechst 33342 (blue) was used as a nuclear counterstain. Images are stacked Z-plane sections from confocal microscopy. Scale bar: 10 um. (B) A relative quantification of VEGF-A expression in the blood vessel wall was performed. The quantification of VEGF-A $\mathrm{A}^{+}$area was determined as a ratio of VEGF-A $\mathrm{A}^{+}$area per total vessel area in the field of view using ImageJ. Data are presented as the mean \pm SEM ( $n=4-8$ vessels $\times 2$ individuals per group); ${ }^{\dagger} P<0.01$, non-diabetic Wt vs. non-diabetic Hifla ${ }^{+>} ;{ }^{*} P<0.001$, non-diabetic Wt vs. diabetic Wt or diabetic Hifla ${ }^{+/}$(2-way ANOVA with Tukey's post-test).

post-transcription, translation, and post-translation levels [48]. Our model provides the first evidence that HIF$1 \alpha$ regulates Vegfa expression in the diabetic heart.
The decreased levels of Vegfa in the $\mathrm{Hifla}^{+/-}$diabetic heart correlate with LV dysfunction and myocardial remodeling. 
Our results are indirectly supported by a study showing that the overexpression of Hifla gene under the control of the myosin heavy chain promoter normalizes VEGF-A levels and inhibits fibrosis in hearts exposed to diabetes [22]. Unfortunately, Xue et al. have not evaluated the echocardiographic functional parameters of the mutant heart to provide a more complex analysis. The protective role of HIF-1 $\alpha$ in acute cardiac ischemia is well known [13,49]. However, the constitutive expression of HIF- $1 \alpha$ and chronic long-term activation of HIF- $1 \alpha$ pathways over time induce cardiomyopathy in transgenic mice with HIF- $1 \alpha$ cardiac-specific overexpression [49]. Thus, a strict regulation of HIF- $1 \alpha$ and its associated adaptive pathways is necessary for the long-term preservation of heart function.

In our study, under normoglycemic conditions, we showed decreased HIF-1 $\alpha$ protein levels in $\mathrm{Hifla}^{+/}$ compared to Wt hearts, reflecting Hifla haploinsufficiency (Figure 4). The reduction of HIF-1 $\alpha$ levels in nuclear fractions from $\mathrm{Hifla}^{+/}$tissues is consistent with other reports $[10,23,24]$. Although HIF- $\alpha$ levels are decreased in $\mathrm{Hifla}^{+-}$mice, these mice are indistinguishable from their Wt littermates but have impaired responses to hypoxia and ischemia $[11,23,24]$. Accordingly, we observed the same phenotype in both Wt and $\mathrm{Hifla}^{+/-}$mice under normoglycemic conditions, including echocardiographic, geometrical, and functional parameters. However, under STZ-induced diabetes, $\mathrm{Hifla}^{+/}$mice exhibited faster deterioration of cardiac functional parameters associated with diabetic cardiomyopathy compared to diabetic Wt mice. Unexpectedly, HIF-1 $\alpha$ protein levels were increased by 2.6 -fold in diabetic hearts of $\mathrm{Hifla}^{+/-}$mutants compared to diabetic $W t$, which may indicate a possible compensation for heterozygosity for the Hif1a knockout allele by changes in the rate of synthesis or degradation of HIF$1 \alpha$ mRNA or protein. However, based on our VEGF-A expression data, the HIF-1a functional activity is affected by the combination of Hif1a haploinsufficiency and diabetes. This is in line with other reports showing that diabetes-reduced VEGF-A expression is the result of decreased HIF- $1 \alpha$ functional activity but not HIF- $1 \alpha$ stabilization $[15,18]$. Furthermore, our results showing decreased VEGF-A and increased TGF- $\beta$ signaling coincide with other reports investigating Hifla gene deletion mutants $[24,45]$.

The most important limitation of our study lies in the global nature of the Hif1a deletion. We are unable to determine which cell type or which combinations of cell types are contributing to the increased susceptibility of $\mathrm{Hifla}^{+/-}$mice to diabetic cardiomyopathy. At the same time, the global deletion of Hifla may affect other tissues and it may indirectly escalate pathological functional and structural changes in the heart of $\mathrm{Hifla}^{+/}$mutants. For example, this may include the neuronal effect of HIF- $1 \alpha$, which may contribute to cardiac dysfunction [13]. Still, our results represent new information, which may have important implications for understanding the mechanisms behind the functional and structural remodeling of the myocardium in response to diabetes.

\section{Conclusions}

According to the data obtained with our mouse model, the loss of Hifla functional allele contributes to the development of diabetic cardiomyopathy. The partial deficiency of Hifla accelerates the progression of diabetic cardiomyopathy by significantly decreasing LV fractional shortening. This functional impairment has been accompanied by changes in the LV transcriptional profile, including Vegfa, and cardiac remodeling. Our results highlight a critical link between diabetes, HIF-1 $\alpha$ regulation, and cardiovascular dysfunction. Furthermore, clinical studies have demonstrated that polymorphisms at the HIF1A locus influence the development of ischemic heart disease and have been associated with type 2 diabetes [50,51]. The results presented in this study further suggest that genetic variation at the HIF1A locus may also influence the increased risk for diabetic cardiomyopathy.

\section{Additional file}

Additional file 1: Primer sequences used for quantitative real-time polymerase chain reaction.

\section{Abbreviations}

HIF-1a: Hypoxia-inducible factor 1a; SIc2a1: Glucose transporter 1; Vegfa: Vascular endothelial growth factor A; Flt1: Vegf receptor-1; Igf2: Insulin-like growth factor 2; Ldha: Lactate dehydrogenase A; Bnip3l: BCL2/adenovirus E1B interacting protein 3-like; Cxadr: Coxsackie virus and adenovirus receptor; $\| 6 s t$ : Interleukin 6 signal transducer; Tgfbr1: Transforming growth factor beta receptor l; Itgav: Integrin alpha V; Pdgfra: Platelet derived growth factor receptor alpha; Gata2: GATA binding protein 2; Ctss: Cathepsin S; Col1: Collagen 1; Cx43: Connexin 43.

\section{Competing interests}

The authors declare that they have no competing interests.

\section{Authors' contributions}

RB designed and performed GPCR experiments and histological analysis. FK designed and performed echocardiographic evaluations. DS designed and performed morphological and morphometric evaluations. LS prepared animals and processed tissues for morphological exams. FP and JN assisted in mice treatment and performed echocardiographic examinations. GP designed the study, analysed data, and wrote the paper. All authors read and approved the final manuscript.

\section{Acknowledgements}

We thank Prof. Gregg L. Semenza, M.D., Ph.D. for providing us with $\mathrm{Hifla}^{+/}$ mutant mice. This work was funded by the Czech Science Foundation (Grant Agreement No. 301/09/0117), by BIOCEV CZ.1.05/1.1.00/02.0109 from the ERDF, and by the Czech Ministry of Education, Youth and Sports (Grant Agreement No. AVOZ50520701).

\section{Author details}

${ }^{1}$ Institute of Biotechnology AS CR, Prague, Czechia. ${ }^{2}$ Institute of Physiology AS CR, Prague, Czechia. ${ }^{3}$ Institute of Anatomy, First Faculty of Medicine, Charles University, Prague, Czechia. ${ }^{4}$ Laboratory of Molecular Pathogenetics, 
Institute of Biotechnology AS CR, v.v.i., Videnska 1083, Prague 4, CZ-142 20, Czechia.

Received: 27 December 2013 Accepted: 28 January 2014

Published: 6 February 2014

\section{References}

1. Boudina S, Abel ED: Diabetic cardiomyopathy, causes and effects. Rev Endocr Metab Disord 2010, 11(1):31-39.

2. Lusis AJ: Atherosclerosis. Nature 2000, 407(6801):233-241.

3. Brownlee M: The pathobiology of diabetic complications: a unifying mechanism. Diabetes 2005, 54(6):1615-1625.

4. Brownlee M: Biochemistry and molecular cell biology of diabetic complications. Nature 2001, 414(6865):813-820.

5. Semenza GL: Oxygen sensing, homeostasis, and disease. New Engl J Med 2011, 365(6):537-547.

6. Bardos II, Ashcroft M: Negative and positive regulation of HIF-1: a complex network. Biochim Biophys Acta 2005, 1755(2):107-120.

7. Haddad JJ, Harb HL: Cytokines and the regulation of hypoxia-inducible factor (HIF)-1alpha. Int Immunopharmacol 2005, 5(3):461-483.

8. Klimova T, Chandel NS: Mitochondrial complex III regulates hypoxic activation of HIF. Cell Death Differ 2008, 15(4):660-666.

9. Chandel NS, McClintock DS, Feliciano CE, Wood TM, Melendez JA, Rodriguez AM, Schumacker PT: Reactive oxygen species generated at mitochondrial complex III stabilize hypoxia-inducible factor-1alpha during hypoxia: a mechanism of $\mathrm{O} 2$ sensing. J Biol Chem 2000, 275(33):25130-25138.

10. Iyer NV, Kotch LE, Agani F, Leung SW, Laughner E, Wenger RH, Gassmann M, Gearhart JD, Lawler AM, Yu AY, et al: Cellular and developmental control of O2 homeostasis by hypoxia-inducible factor 1 alpha. Genes Dev 1998, 12(2):149-162.

11. Li J, Bosch-Marce M, Nanayakkara A, Savransky V, Fried SK, Semenza GL, Polotsky VY: Altered metabolic responses to intermitternt hypoxia in mice with partial deficiency of hypoxia-inducible factor $1 \mathrm{a}$. Physiol Genom 2006, 25(3):450-457.

12. Kline DD, Peng YJ, Manalo DJ, Semenza GL, Prabhakar NR: Defective carotid body function and impaired ventilatory responses to chronic hypoxia in mice partially deficient for hypoxia-inducible factor 1 alpha. Proc Natl Acad Sci USA 2002, 99(2):821-826.

13. Cai Z, Zhong H, Bosch-Marce M, Fox-Talbot K, Wang L, Wei C, Trush MA, Semenza GL: Complete loss of ischaemic preconditioning-induced cardioprotection in mice with partial deficiency of HIF-1 alpha. Cardiovasc Res 2008, 77(3):463-470.

14. Huang Y, Hickey RP, Yeh JL, Liu D, Dadak A, Young LH, Johnson RS, Giordano FJ: Cardiac myocyte-specific HIF-1alpha deletion alters vascularization, energy availability, calcium flux, and contractility in the normoxic heart. Faseb J 2004, 18(10):1138-1140.

15. Botusan IR, Sunkari VG, Savu O, Catrina Al, Grunler J, Lindberg S, Pereira T, Yla-Herttuala S, Poellinger L, Brismar K, et al: Stabilization of HIF-1alpha is critical to improve wound healing in diabetic mice. Proc Natl Acad Sci USA 2008, 105(49):19426-19431.

16. Liu L, Marti GP, Wei X, Zhang X, Zhang H, Liu Y, Nastai M, Semenza GL, Harmon JW: Age-dependent impairment of HIF-1alpha expression in diabetic mice: correction with electroporation-facilitated gene therapy increases wound healing, angiogenesis, and circulating angiogenic cells. J Cell Physiol 2008, 217(2):319-327.

17. Catrina SB, Okamoto K, Pereira T, Brismar K, Poellinger L: Hyperglycemia regulates hypoxia-inducible factor-1alpha protein stability and function. Diabetes 2004, 53(12):3226-3232.

18. Thangarajah H, Yao D, Chang El, Shi Y, Jazayeri L, Vial IN, Galiano RD, Du XL, Grogan R, Galvez MG, et al: The molecular basis for impaired hypoxia-induced VEGF expression in diabetic tissues. Proc Natl Acad Sci USA 2009, 106(32):13505-13510.

19. Chou E, Suzuma I, Way KJ, Opland D, Clermont AC, Naruse K, Suzuma K, Bowling NL, Vlahos CJ, Aiello LP, et al: Decreased cardiac expression of vascular endothelial growth factor and its receptors in insulin-resistant and diabetic States: a possible explanation for impaired collateral formation in cardiac tissue. Circulation 2002, 105(3):373-379.

20. Yoon YS, Uchida S, Masuo O, Cejna M, Park JS, Gwon HC, Kirchmair R, Bahlman F, Walter D, Curry C, et al: Progressive attenuation of myocardial vascular endothelial growth factor expression is a seminal event in diabetic cardiomyopathy: restoration of microvascular homeostasis and recovery of cardiac function in diabetic cardiomyopathy after replenishment of local vascular endothelial growth factor. Circulation 2005, 111(16):2073-2085.

21. Mizushige K, Yao L, Noma T, Kiyomoto H, Yu Y, Hosomi N, Ohmori K, Matsuo $\mathrm{H}$ : Alteration in left ventricular diastolic filling and accumulation of myocardial collagen at insulin-resistant prediabetic stage of a type II diabetic rat model. Circulation 2000, 101(8):899-907.

22. Xue W, Cai L, Tan Y, Thistlethwaite P, Kang YJ, Li X, Feng W: Cardiac-specific overexpression of HIF-1\{alpha\} prevents deterioration of glycolytic pathway and cardiac remodeling in streptozotocin-induced diabetic mice. Am J Pathol 2010, 177(1):97-105.

23. Peng YJ, Yuan G, Ramakrishnan D, Sharma SD, Bosch-Marce M, Kumar GK, Semenza GL, Prabhakar NR: Heterozygous HIF-1alpha deficiency impairs carotid body-mediated systemic responses and reactive oxygen species generation in mice exposed to intermittent hypoxia. J Physiol 2006, 577(Pt 2):705-716.

24. Bosch-Marce M, Okuyama H, Wesley JB, Sarkar K, Kimura H, Liu YV, Zhang H, Strazza M, Rey S, Savino L, et al: Effects of aging and hypoxia-inducible factor- 1 activity on angiogenic cell mobilization and recovery of perfusion after limb ischemia. Circ Res 2007, 101(12):1310-1318.

25. Bohuslavova R, Kolar F, Kuthanova L, Neckar J, Tichopad A, Pavlinkova G: Gene expression profiling of sex differences in HIF1-dependent adaptive cardiac responses to chronic hypoxia. J Appl Physiol 2010, 109(4):1195-1202.

26. Pavlinkova G, Salbaum JM, Kappen C: Maternal diabetes alters transcriptional programs in the developing embryo. BMC Genom 2009, 10:274.

27. Pfaffl MW: A new mathematical model for relative quantification in real-time RT-PCR. Nucleic Acids Res 2001, 29(9):e45.

28. Bohuslavova R, Skvorova L, Sedmera D, Semenza GL, Pavlinkova G: Increased susceptibility of HIF-1alpha heterozygous-null mice to cardiovascular malformations associated with maternal diabetes. J Mol Cell Cardiol 2013, 60:129-141.

29. Sato T, Haimovici R, Kao R, Li AF, Roy S: Downregulation of connexin 43 expression by high glucose reduces gap junction activity in microvascular endothelial cells. Diabetes 2002, 51(5):1565-1571.

30. Boudina S, Abel ED: Diabetic cardiomyopathy revisited. Circulation 2007, 115(25):3213-3223

31. Poornima IG, Parikh P, Shannon RP: Diabetic cardiomyopathy: the search for a unifying hypothesis. Circ Res 2006, 98(5):596-605.

32. Yu X, Tesiram YA, Towner RA, Abbott A, Patterson E, Huang S, Garrett MW, Chandrasekaran S, Matsuzaki S, Szweda LI, et al: Early myocardial dysfunction in streptozotocin-induced diabetic mice: a study using in vivo magnetic resonance imaging (MRI). Cardiovasc Diabetol 2007, 6:6.

33. Chang KC, Lo HM, Tseng YZ: Systolic elastance and resistance in the regulation of cardiac pumping function in early streptozotocin-diabetic rats. Exp Biol Med 2002, 227(4):251-259.

34. Hoit BD, Castro C, Bultron G, Knight S, Matlib MA: Noninvasive evaluation of cardiac dysfunction by echocardiography in streptozotocin-induced diabetic rats. J Card Fail 1999, 5(4):324-333.

35. Caruso L, Yuen S, Smith J, Husain M, Opavsky MA: Cardiomyocyte-targeted overexpression of the coxsackie-adenovirus receptor causes a cardiomyopathy in association with beta-catenin signaling. J Mol Cell Cardiol 2010, 48(6):1194-1205.

36. Zuliani G, Galvani M, Maggio M, Volpato S, Bandinelli S, Corsi AM, Lauretani F, Cherubini A, Guralnik JM, Fellin R, et al: Plasma soluble gp130 levels are increased in older subjects with metabolic syndrome. The role of insulin resistance. Atherosclerosis 2010, 213(1):319-324.

37. Zymek P, Bujak M, Chatila K, Cieslak A, Thakker G, Entman ML, Frangogiannis NG: The role of platelet-derived growth factor signaling in healing myocardial infarcts. J Am Coll Cardiol 2006, 48(11):2315-2323.

38. Sokolovska J, Isajevs S, Sugoka O, Sharipova J, Lauberte L, Svirina D, Rostoka E, Sjakste T, Kalvinsh I, Sjakste N: Correction of glycaemia and GLUT1 level by mildronate in rat streptozotocin diabetes mellitus model. Cell Biochem Funct 2011, 29(1):55-63.

39. Yamashita K, Discher DJ, Hu J, Bishopric NH, Webster KA: Molecular regulation of the endothelin-1 gene by hypoxia. Contributions of hypoxia-inducible factor-1, activator protein-1, GATA-2, AND p300/CBP. J Biol Chem 2001, 276(16):12645-12653.

40. Linnemann AK, O'Geen H, Keles S, Farnham PJ, Bresnick EH: Genetic framework for GATA factor function in vascular biology. Proc Natl Acad Sci USA 2011, 108(33):13641-13646. 
41. de Nooijer R, Bot I, von der Thusen $J H$, Leeuwenburgh MA, Overkleeft HS, Kraaijeveld AO, Dorland R, van Santbrink PJ, van Heiningen SH, Westra MM, et al: Leukocyte cathepsin $\mathrm{S}$ is a potent regulator of both cell and matrix turnover in advanced atherosclerosis. Arterioscler Thromb Vasc Biol 2009, 29(2):188-194.

42. Eltzschig HK, Carmeliet P: Hypoxia and inflammation. New Engl J Med 2011, 364(7):656-665.

43. Wu L, Derynck R: Essential role of TGF-beta signaling in glucose-induced cell hypertrophy. Dev Cell 2009, 17(1):35-48.

44. Sanchez-Elsner T, Botella LM, Velasco B, Corbi A, Attisano L, Bernabeu C: Synergistic cooperation between hypoxia and transforming growth factor-beta pathways on human vascular endothelial growth factor gene expression. J Biol Chem 2001, 276(42):38527-38535.

45. Wei H, Bedja D, Koitabashi N, Xing D, Chen J, Fox-Talbot K, Rouf R, Chen S, Steenbergen C, Harmon JW, et al: Endothelial expression of hypoxia-inducible factor 1 protects the murine heart and aorta from pressure overload by suppression of TGF-beta signaling. Proc Natl Acad Sci USA 2012, 109(14):E841-E850

46. Cai L, Li W, Wang G, Guo L, Jiang Y, Kang YJ: Hyperglycemia-induced apoptosis in mouse myocardium: mitochondrial cytochrome C-mediated caspase-3 activation pathway. Diabetes 2002, 51(6):1938-1948.

47. Marfella R, D'Amico M, Di Filippo C, Piegari E, Nappo F, Esposito K, Berrino L, Rossi F, Giugliano D: Myocardial infarction in diabetic rats: role of hyperglycaemia on infarct size and early expression of hypoxia-inducible factor 1. Diabetologia 2002, 45(8):1172-1181.

48. Pereira ER, Liao N, Neale GA, Hendershot LM: Transcriptional and post-transcriptional regulation of proangiogenic factors by the unfolded protein response. PloS one 2010, 5(9). doi:10.1371/journal.pone.0012521.

49. Holscher M, Schafer K, Krull S, Farhat K, Hesse A, Silter M, Lin Y, Pichler BJ, Thistlethwaite P, El-Armouche A, et al: Unfavourable consequences of chronic cardiac HIF-1alpha stabilization. Cardiovasc Res 2012, 94(1):77-86.

50. Yamada N, Horikawa Y, Oda N, lizuka K, Shihara N, Kishi S, Takeda J: Genetic variation in the hypoxia-inducible factor-1alpha gene is associated with type 2 diabetes in Japanese. J Clin Endocrinol Metab 2005, 90(10):5841-5847.

51. Hlatky MA, Quertermous T, Boothroyd DB, Priest JR, Glassford AJ, Myers RM, Fortmann SP, Iribarren C, Tabor HK, Assimes TL, et al: Polymorphisms in hypoxia inducible factor 1 and the initial clinical presentation of coronary disease. Am Heart J 2007, 154(6):1035-1042.

doi:10.1186/1472-6823-14-11

Cite this article as: Bohuslavova et al:: Partial deficiency of HIF-1a stimulates pathological cardiac changes in streptozotocin-induced diabetic mice. BMC Endocrine Disorders 2014 14:11.

\section{Submit your next manuscript to BioMed Central and take full advantage of:}

- Convenient online submission

- Thorough peer review

- No space constraints or color figure charges

- Immediate publication on acceptance

- Inclusion in PubMed, CAS, Scopus and Google Scholar

- Research which is freely available for redistribution

Submit your manuscript at www.biomedcentral.com/submit
Biomed Central 